\title{
The complexity of climate reconstructions using the coexistence approach on Qinghai-Tibetan Plateau
}

\author{
Zhi-Yong Zhang ${ }^{1,2^{*}}$, Dong-Mei Cheng ${ }^{1}$, Cheng-Sen $\mathrm{Li}^{2^{*}}$, Wan Hu${ }^{1}$, Xuan-Huai Zhan ${ }^{1}$ and Hong-Li ji ${ }^{1}$
}

\begin{abstract}
Quantifying the palaeoclimates of Qinghai-Tibetan Plateau is vital for understanding the uplift history of plateau and the evolution of Asian monsoon since Cenozoic. Recently, the Coexistence Approach (CA) has been employed to reconstruct the palaeoelevation and palaeoclimate of the plateau by several studies. However, the application of CA in mountainous areas and the realism of climate reconstructions via this method are seldom discussed, although the complexity of reconstructions is speculated. Here we reevaluated the realism of climate reconstruction using the CA with modern pollen samples from the Qinghai-Tibetan Plateau, and try to explore the possible factors influencing the precipitation and temperature reconstructions by CA. We suggest that the long-distance transport pollen as a result of the Asian summer monsoon potentially significantly affects the reconstructions both for precipitation and temperature. The precipitation complexly interacting with snowmelt and permafrost thaw leads to the discrepancy between the reconstructed precipitation and the real value. The response temperature for blossoming of dwarfed plants on the plateau is mostly likely higher than the air temperature (usually measured at $1.5 \mathrm{~m}$ above ground) due to energy flux or morphological adaptation of inflorescences during the growing season, causing the distortion of temperature reconstructions. Precipitation reconstruction is notoriously difficult as the establishers of CA have already suggested, but reconstructing the low temperatures may be even more challenging on Qinghai-Tibetan Plateau. Though all of the explorations in current paper are in a qualitative way, it offers an inspiration of how appropriately interpret the disagreements between CA results and the observations, and of how to obtain a reasonable reconstruction of palaeoclimate of the plateau.
\end{abstract}

Keywords: Complexity, Climate reconstruction, Coexistence approach, Modern pollen assemblages, Qinghai-Tibetan Plateau

\section{Introduction}

The Coexistence Approach (CA) is a plant-based method to reconstruct palaeoclimates, in which the climatic envelopes for each species found in a fossil assemblage are superimposed and the climate interval common to all species is assumed to represent the climate of the sampling site (Mosbrugger and Utescher 1997; Utescher et al. 2014; Zhang 2016). It has been widely used to reconstruct the palaeoenvironments of Eurasia (e.g. Mosbrugger and Utescher 1997; Gebka et

\footnotetext{
*Correspondence: zzyzwx@126.com; lics@ibcas.ac.cn

${ }^{1}$ Lushan Botanical Garden, Jiangxi Province and Chinese Academy of Sciences, Jiujiang 332900, Jiangxi Province, China

${ }^{2}$ State Key Laboratory of Systematic and Evolutionary Botany, Institute of Botany, Chinese Academy of Sciences, Xiangshan, Beijing 100093, China
}

al. 1999; Pross et al. 2000; Bruch et al. 2006; Böhme et al. 2007; Erdei et al. 2007; Yang et al. 2007; Li et al. 2009; Xia et al. 2009; Yao et al. 2009; Hao et al. 2010; Grein et al. 2011; Jacques et al. 2011; Qin et al. 2011; Quan et al. 2011; Utescher et al. 2014; Zhang et al. 2016; Wu et al. 2018), except for mountainous areas of China and the Himalaya. There are great complexities for palaeoclimate reconstructions in these high altitudinal regions as pointed out by previous studies (Mosbrugger and Utescher 1997; Song et al. 2010; Grimm and Denk 2012; Zhang et al. 2015), due to a variety of reasons. For instance, water availability for plant growth may vary considerably over a very short distance by reason of partitions of precipitation and groundwater. This could consistently lead to the disagreements between the 
reconstructed precipitation parameters and the real value (Mosbrugger and Utescher 1997). The mechanism of species coexistence in water-limited ecosystems like Qinghai-Tibetan Plateau is particularly different to other ecosystems, assuming that trees and grasses display differential access to the insufficient water because of their spatial difference in rooting distributions (Cable 1969; Knoop and Walker 1985; Kambatuku et al. 2013; Ying et al. 2017). In addition, shortage of meteorological stations as references to the reconstructed climates is constraining the ability of reducing reconstruction uncertainties.

Nevertheless, in recent years several studies have tried to reconstruct the palaeoelevation and palaeoclimates from Oligocene to Eocene on Qinghai-Tibetan Plateau by using CA (Song et al. 2010; Sun et al. 2014; Wu et al. 2018). These reconstructions provide strong evidences of the uplift history of plateau and are helpful in understanding main aspects of the global climate change, collision tectonics and the evolution of the Asian monsoon since the Cenozoic. However, the reconstructed method itself, i.e. CA is lately critically evaluated by modern-day data (Grimm and Denk 2012), and even the effectiveness of reconstructing palaeoclimates via $\mathrm{CA}$ has also been doubted (Grimm and Potts 2016; Grimm et al. 2016). For above reasons, the application of CA on QinghaiTibetan Plateau is in urgent need of thoughtful consideration before a reasonable palaeoclimate reconstruction is made. Zhang et al. (2015) is the first study to evaluate the realism of climate reconstructions using the method of CA with modern pollen samples from the QinghaiTibetan Plateau. They found that precipitation reconstructions are better than temperature reconstructions. Moreover, the presence of arboreal pollen, most of which is derived from outside the region, distorts all of the reconstructions; and more reliable climate reconstructions can be made by excluding possible arboreal contaminants. Although three different ways of CA application for climate reconstructions have been explored and the potential reasons of why the reconstructed climates were not in agreement with the observed values were discussed (Zhang et al. 2015), reconsiderations on this problem of disagreements are forming some new insights.

Here, we revisit the paper of Zhang et al. (2015) and discuss some possible factors affecting climate reconstructions for CA application on Qinghai-Tibetan Plateau. The discussion is in a more qualitative way because the detailed mechanism for those influential factors is too complicated, such as the dynamic interactions among precipitation, snowmelt and permafrost thaw. Nevertheless, it would be useful to appropriately interpret the reconstructed (palaeo-) climates of the plateau and surrounding area via the method of CA.

\section{Methods and materials}

\subsection{Study area and climate data}

The Qinghai-Tibetan Plateau is one of the highest mountains in the world with an average elevation of over $4000 \mathrm{~m}$ above sea level (Fig. 1) (Liu and Chen 2000). Delimitations of the plateau are generally the Hengduan Mountains in the east, the Himalayan Mountains in the south, the Karakorum Range of Pakistan in the west, and the Qilian and the Kunlun Mountains in the north (Zhang et al. 2002). The vegetation of the plateau includes deserts in the northern part of the plateau, alpine vegetation in the central part, subtropical broad-leaved evergreen forest region in the west and south, and tropical monsoon and tropical rainforests on the southern slopes of the Himalayas. This diverse vegetation pattern is a result of the particular plateau climate, which is dominated by the Indian monsoon during summer and by the westerlies during winter (Zhang 2007). The strong climatic gradients of mean annual precipitation (MAP), mean annual temperature (MAT), mean temperature of the warmest month (MTWA), and mean temperature of the coldest month (MTCO) are shown in Fig. 1. On this set of climate parameters, we used a baseline $1-\mathrm{km}$ resolution gridded climatology constructed from mean monthly values of temperature, precipitation and percentage of possible sunshine hours, derived by an elevation-sensitive spline interpolation from 1814 meteorological stations across China (Harris et al. 2013; Wang et al. 2013). Of these, 740 stations have observations during the years 1971-2000 and the remaining stations have observations during the years 1981-1990.

\subsection{Modern pollen data and method of climate reconstruction}

Here we revisit the pollen data published by Zhang et al. (2015). They collected forty-four surface soil samples along a transect from Qinghai Lake, across the central part of the Qinghai-Tibetan Plateau towards Lhasa (Fig. 1). Seventy pollen types were identified from these samples. The dominants of pollen assemblages are non-arboreal pollen (NAP) $(73.1 \%$ in average) and shrubs (5.5\%), while arboreal pollen (AP) comprises $15.9 \%$ of the assemblages. The climate of each pollen-sampling site was taken as that of the $1 \times 1 \mathrm{~km}^{2}$ aforementioned gridcell where the site occurred. It indicates the observed climate. They simulated the modern climate based on the pollen data of surface soil by the Coexistence Approach (CA), and compared with the observed climates across 44 sampling sites. In this study, only the weighted reconstruction (WR) and the non-tree reconstruction (NTR) in the framework of CA conducted by Zhang et al. (2015) are employed to make the point of climate reconstruction discrepancies between CA results and the observations (Table 1). Rare 

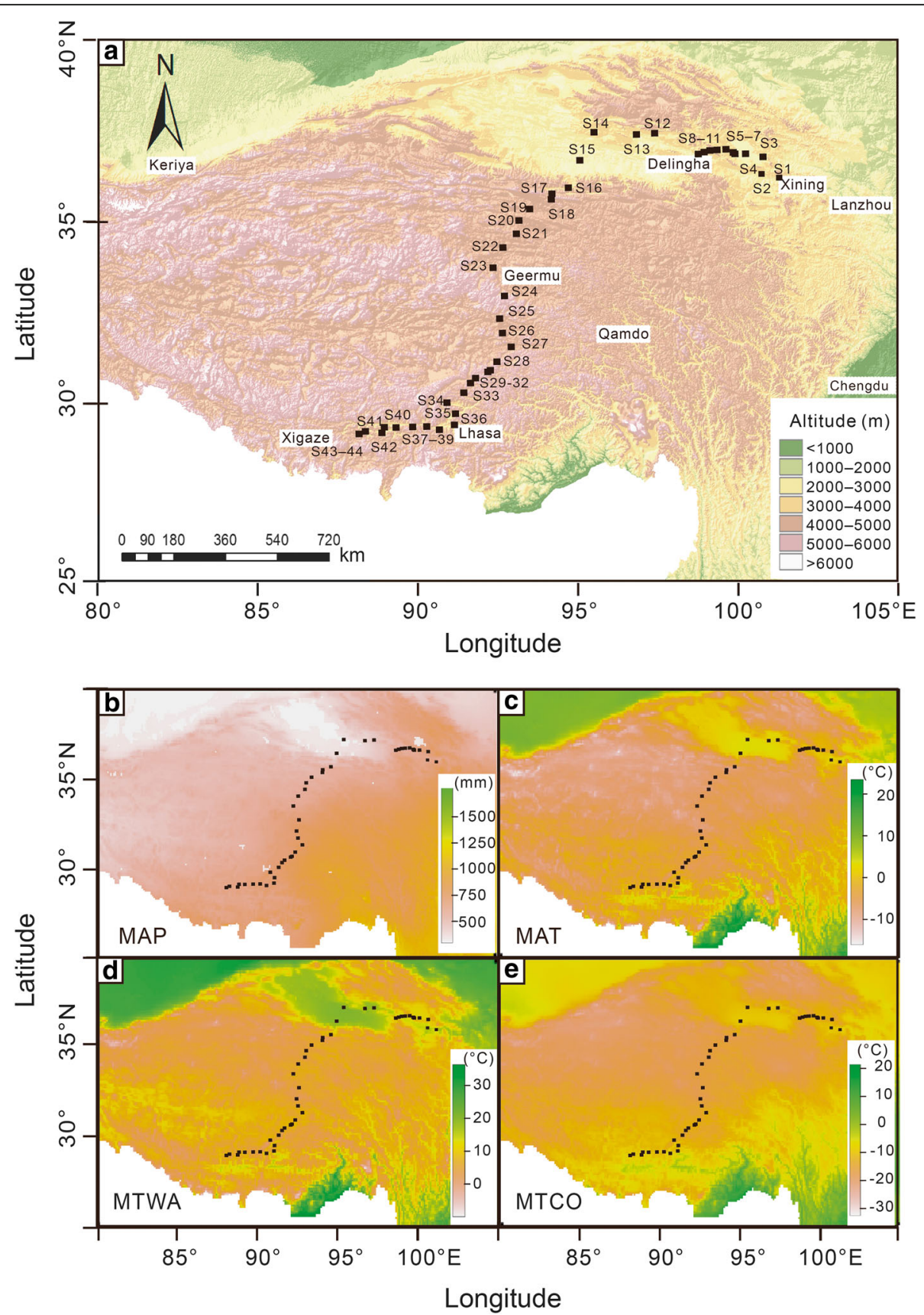

Fig. 1 a Location of the study sites. The sites (closed black squares, numbered as S1-S44) are superimposed on maps showing the digital elevation. Please see sites details in Zhang et al. 2015; b-e Climatic gradients for the sampling sites. MAP Mean annual precipitation, MAT Mean annual temperature, MTWA Mean temperature of the warmest month, MTCO Mean temperature of the coldest month. The climate data from 1814 meteorological stations across China were interpolated to the $1-\mathrm{km}$ resolution grid using smoothing spline interpolation (ANUSPLIN version 4.36; Hancock and Hutchinson 2006) and the Shuttle Radar Topography Mission (SRTM) 1-km digital elevation model (Farr et al. 2007)

pollen taxa with less than $1 \%$ of pollen assemblage were excluded through the analysis because they possibly represent highly localized environmental or climatic conditions and bias the reconstructions of regional climate. The effect of potential exotic tree pollen on climate reconstructions is tested.
The Coexistence Approach is a quantitative method of palaeoclimate reconstruction that is frequently employed by many scientists to retrace the palaeoclimates of Eurasian continents (e.g. Mosbrugger and Utescher 1997; Bruch et al. 2006; Erdei et al. 2007; Yang et al. 2007; Xia et al. 2009; Yao et al. 2009; Jacques et al. 2011; Qin et al. 


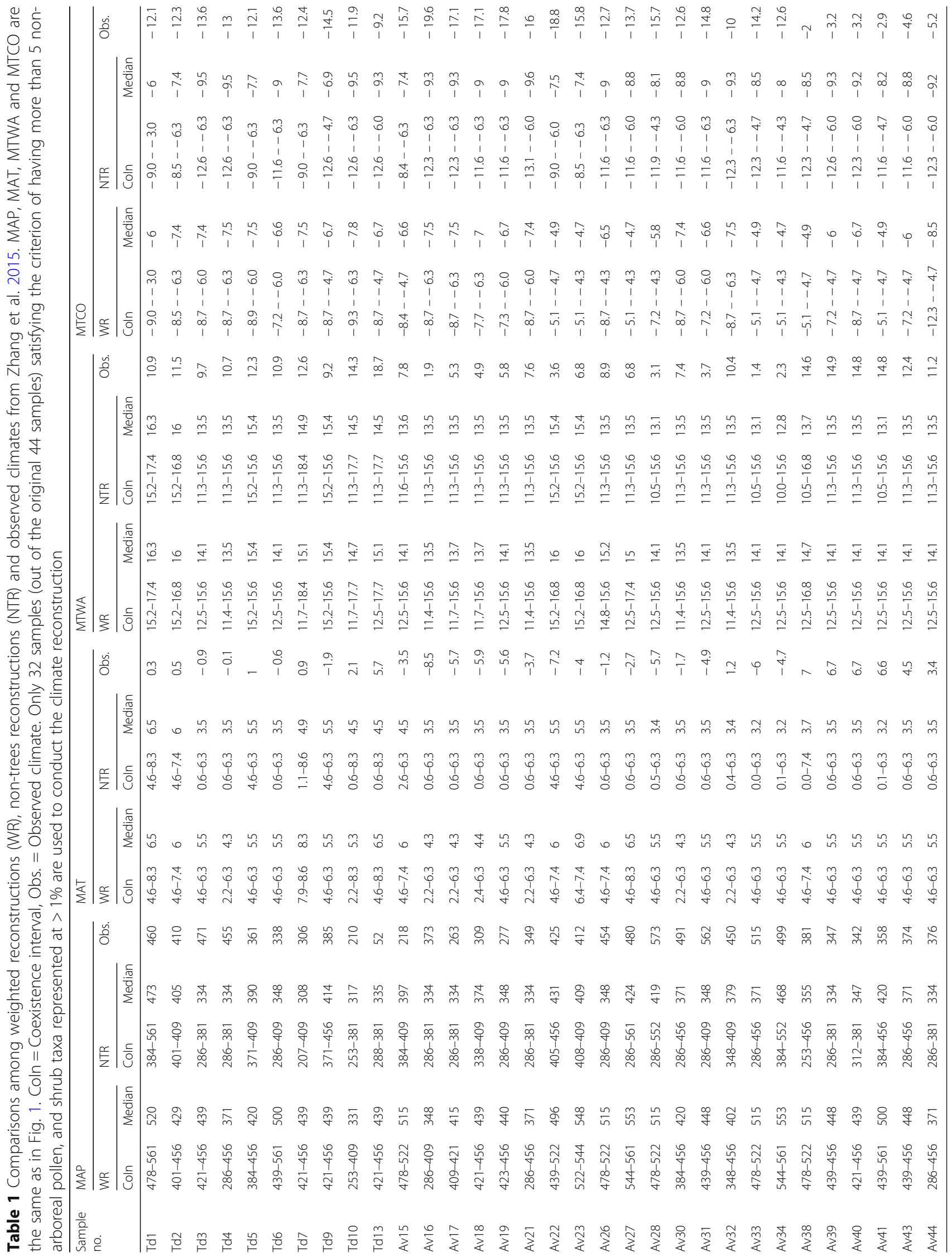


2011; Quan et al. 2011; Utescher et al. 2014). However, it still needs to be continuously evaluated by using data from various environments (Grimm and Denk 2012), such as in the region of Qinghai-Tibetan Plateau (Zhang et al. 2015). So far, rare studies have indeed used the Coexistence Approach to reconstruct the palaeoclimates of Qinghai-Tibetan Plateau (but to reconstruct palaeoelevations of the plateau, e.g. Song et al. 2010; Sun et al. 2014; Wu et al. 2018).

\section{Results and discussion}

\subsection{Influence of long-distance transported pollen on climate reconstructions}

Pollen transportation with long distance on Qinghai-Tibetan Plateau has already been found in several studies (e.g. Cour et al. 1999; Yu et al. 2001; Jiang and Ding 2009; Lu et al. 2010; Zhang et al. 2018). This kind of pollen is mostly the anemophilous tree pollen (Fig. 2), typical taxa like Abies, Pinus and Betula (Zhang and Li
2017). They have been transported decades or hundreds of kilometers away by the Asian summer monsoon from the southeast of the plateau to the central part (Zhang et al. 2015), even to the northwest part (Cour et al. 1999). For this reason, they become exotic pollen in contrast to the local pollen assemblage. However, studies seldom assess the extent of influence of long-distance transported pollen on climate reconstruction until Zhang et al. (2015).

Difference between NTR and observations vs. difference between WR and observations suggests that NTR is better than WR for all climatic variables because the former differences are comparably smaller than the latter one (Fig. 3). Analysis of t-test has further verified the significant ( $p$-value $<0.01$ for MAP, MAT, MTWA and MTCO) influence of potential exotic tree pollen on the climate reconstructions. Due to contamination of tree pollen sourced from the southeastern part of the plateau, the reconstructed climates by the method of CA are remarkably higher than the observed climates both for

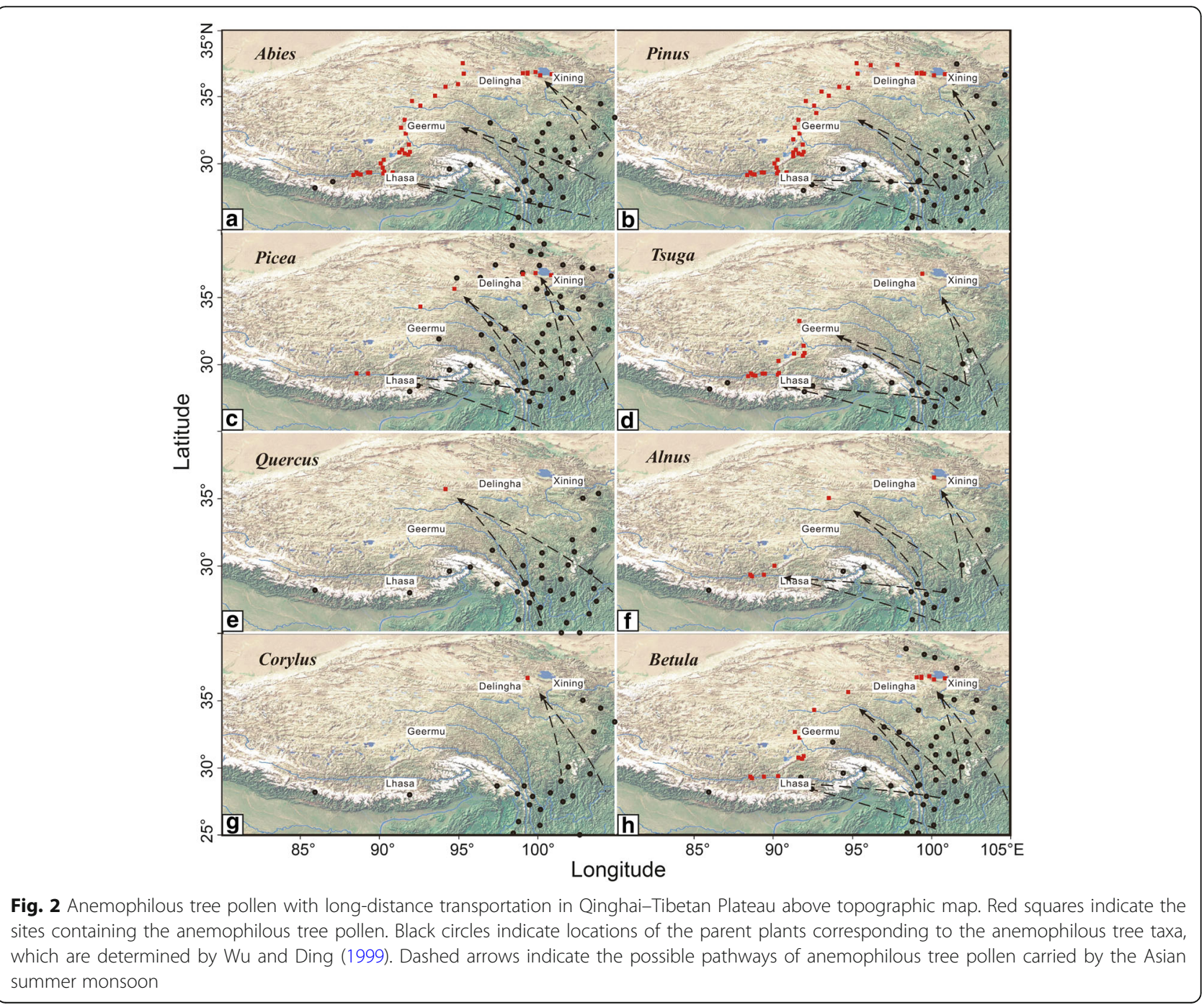



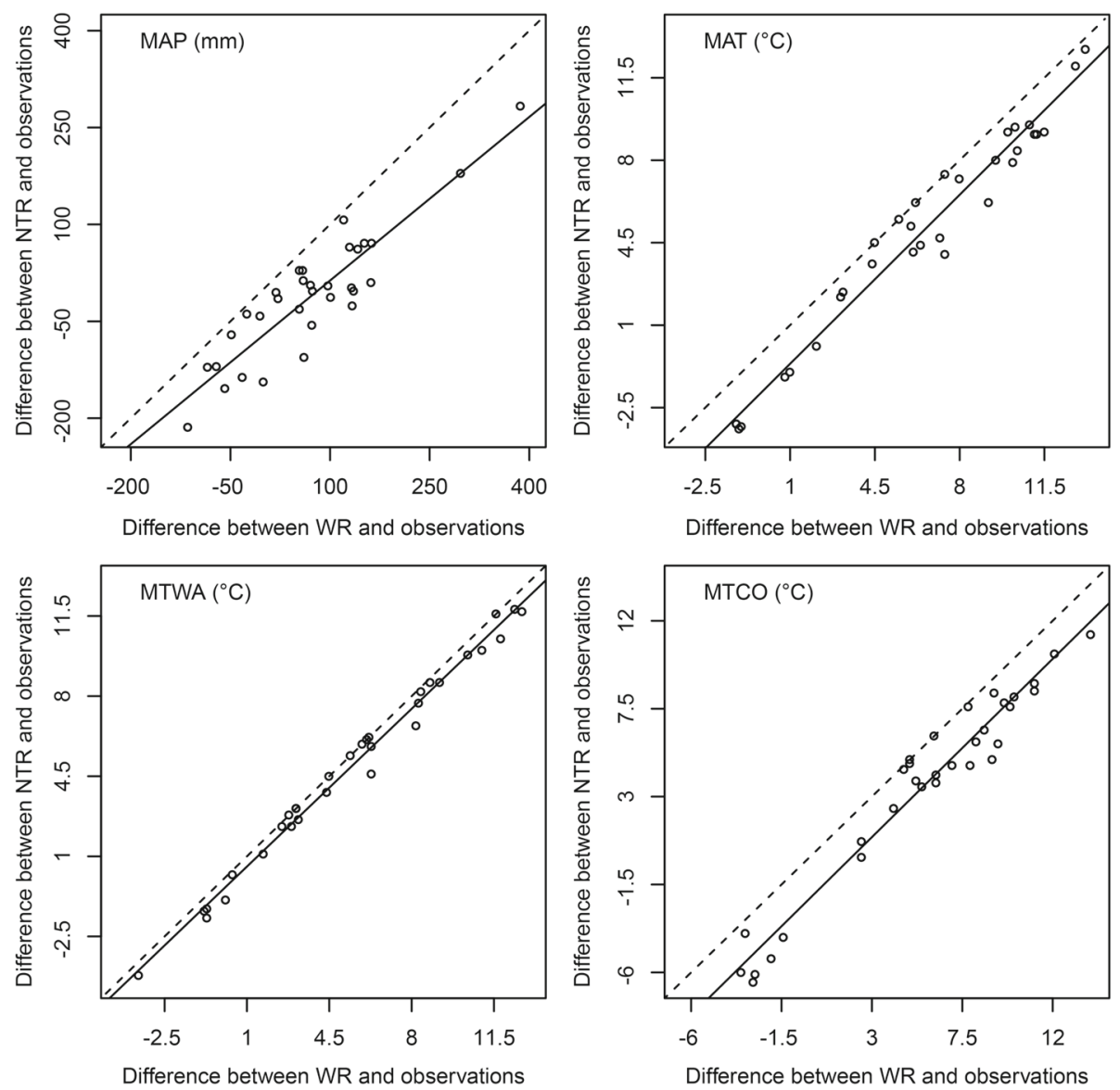

Fig. 3 Comparison difference between the weighted reconstruction (WR) and observations with difference between the non-trees reconstruction (NTR) and observations for MAP, MAT, MTWA and MTCO. MAP Mean annual precipitation, MAT Mean annual temperature, MTWA Mean temperature of the warmest month, MTCO Mean temperature of the coldest month. Dashed line is 1:1 line. Solid line indicates the linear regression line

precipitation and temperatures (Zhang et al. 2015). On the central part of Qinghai-Tibetan Plateau, the vegetation is mostly non-forest as a result of mountain blockages on Asian summer monsoon. Thus, it is really important to identify the exotic tree pollen from local pollen assemblages. Usually, trees need more rainfall and higher temperatures than shrubs and herbs do. Therefore, it is not surprising that the reconstructed precipitation and temperatures are higher than the real climates because of the inclusion of tree pollen.

\subsection{Influence of snowmelt and permafrost thaw on MAP reconstruction}

In the paper of Zhang et al. (2015), they found that the reconstructed precipitation is higher than the observed at $72 \%$ of the sampling sites, and in $83 \%$ of these cases the reconstructed MAP is at least $50 \%$ higher than the observed MAP; the root mean squared error (RMSE) is nearly $100 \mathrm{~mm}$ between the reconstructed MAP and the observed values in terms of non-trees reconstruction. Although this relatively intermediate error is acceptable for palaeoclimate reconstructions (Mosbrugger and Utescher 1997; Wilf et al. 1998), it also pinpoints a problem of what causes this discrepancy for MAP.

As Mosbrugger and Utescher (1997) mentioned, the reconstruction of precipitation is very difficult partly because precipitation and groundwater availability may vary remarkably over a short distance. On Qinghai-Tibetan Plateau, the groundwater availability is susceptible both to the snowmelt and permafrost thaw. Qian et al. (2003) described the deepest (between $85^{\circ} \mathrm{E}$ and $90^{\circ} \mathrm{E}$ along $30^{\circ} \mathrm{N}$ ) and the second (with a center located at $95^{\circ}$ $\mathrm{E}$ and $33^{\circ} \mathrm{N}$ ) deepest winter snow centers and the range for annual variation of winter snow on Qinghai-Tibetan Plateau. The snow depth varies more in areas of deeper snow cover. The interannual variation is less than $30 \mathrm{~cm}$ in northern sampling region, but over $40 \mathrm{~cm}$ in southern 


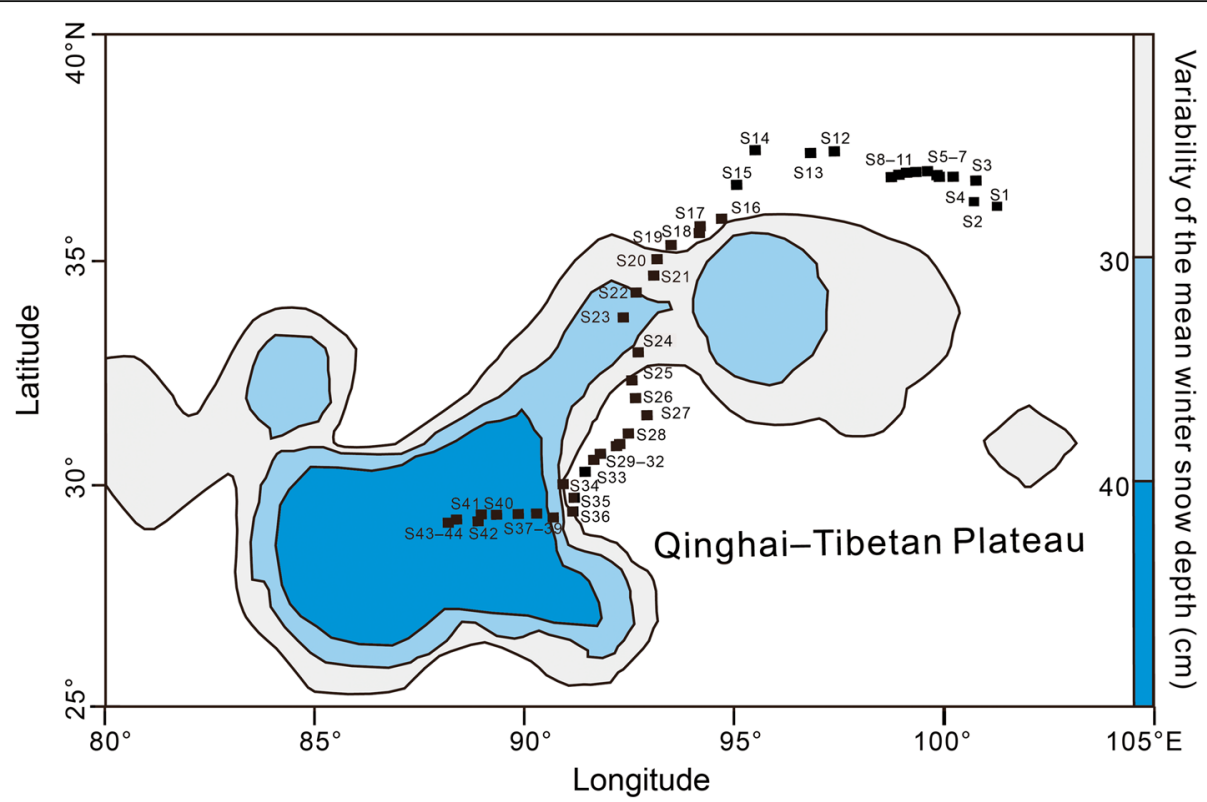

Fig. 4 Distributions of variability of the mean winter snow depth (cm). Redrawn from Qian et al. (2003). The sampling sites are the same as in Fig. 1. Areas with different colors indicate the variability of the mean winter snow depth

sampling region. For the sampling sites from the central part of the plateau, this variation differs from $20 \mathrm{~cm}$ to $50 \mathrm{~cm}$ (Fig. 4).

Although variability of the mean winter snow depth from Qian et al. (2003) is based on 78 snow stations on the Qinghai-Tibetan Plateau and its surrounding area for the years between 1957 and 1998, it has illustrated that snowmelt is definitely a partition of water availability for plateau plants. As snow depth increases, soil moisture also increases, but the relationship is not linear; eventually, as a result of long-term adaptation to deep snow cover, many species on the plateau repeatedly able to tolerate a shortened growing season have become ephemeral or endemic (Chen et al. 2008).

Permafrost represents another source of groundwater for the local floras. The thaw of permafrost in Tuotuohe and Amdo of the eastern Qinghai-Tibetan Plateau can create wet soil and store about $16 \%$ of annual precipitation (Zhang et al. 2003). At the few sites where the reconstructed MAP is lower than the observed MAP (Zhang et al. 2015) the local flora is expected to be short of rainfall in terms of MAP. However, we think plants still can survive and ordinarily produce their pollen due to the complementary contributions from snowmelt and permafrost thaw. On Qinghai-Tibetan Plateau, also an arid and semi-arid ecosystem, species coexistence has quite extraordinary mechanism that trees and grasses could display differential access to the limited water resource because their rooting systems can distribute in different depths. This vertical niche separation mechanism is first proposed by Walter (1971) and then approved by many studies (e.g. Cable 1969; Knoop and Walker 1985; Kambatuku et al. 2013; Ying et al. 2017). Of course, how the detailed mechanism of the hydrologic processes among rainfall, snowmelt and permafrost works for plants should be investigated further in the future. It would be helpful in correcting the discrepancy of reconstructed MAP versus the observations in the framework of CA. After all, large discrepancies occurred in some cases (e.g., up to $214 \mathrm{~mm}$ for site 23; Table 1).

\subsection{Differences between air and blossoming temperature} Zhang et al. (2015) showed that the reconstructed temperatures, MAT, MTWA and MTCO, have warm biases in most cases except for the sites closer to the south of plateau, no matter what reconstruction way has been used. RMSEs are $6.6^{\circ} \mathrm{C}, 6.4{ }^{\circ} \mathrm{C}$ and $6.2^{\circ} \mathrm{C}$ between the reconstructed temperatures and the observed values for MAT, MTWA and MTCO, respectively. These large errors not only illustrate that the CA reconstructions of temperature are problematic, but also lead us to inevitably ask the question of why the reconstructed temperatures are so much higher than the observations.

Harsh environments like low temperature seriously restrict plant growth (Sharma et al. 2005), especially on Qinghai-Tibetan Plateau. Because of this, many plants have very short growing periods around a year and are suppressed and dwarfed in appearance as well. For instance, several species of Salix live as a blanket covering with a height of only decades of centimeters (Kang et al. 2011). Shrubs and herbs in such high altitudes could just 
bloom and produce pollen during the growing season when the air temperature (usually measured at ca. $1.5 \mathrm{~m}$ height by air thermometer) exceeds the least temperature requirement for the local flora. However, the reconstructed MTWA (median of the coexistence interval) is much higher than the real temperature. On the other hand, the air temperature all year round is lower than the soil temperature at $5 \mathrm{~cm}$ depth in the alpine meadow $(\mathrm{Gu}$ et al. 2005). For example, if the air temperature is $9.1^{\circ} \mathrm{C}$, the soil temperature at $5 \mathrm{~cm}$ depth can be up to $14.8^{\circ} \mathrm{C}$. This means the temperature of blossoming that shrubs and herbs on the plateau respond to could be much closer to the soil temperature rather than the air temperature (Fig. 5). As Gu et al. (2005) explained, energy flux changes dramatically during the growth period compared to the non-growth period. At the period of plant growth, latent heat flux rapidly increases and sensible heat flux decreases due to the increases in precipitation and vegetation. This phenomenon could be particular relevant at sites with the altitudes of less than $3000 \mathrm{~m}$ on the eastern plateau. The actual mechanism of blossoming responding to temperature could be more complicated at other sites from Zhang et al. (2015). For sites over $4000 \mathrm{~m}$ altitude on the plateau, "snowball plants" like many Saussurea species (Tsukaya and Tsuge 2001; Kita et al. 2004) and "glasshouse plants" like Rheum nobile (Tsukaya and Tsuge 2001) often distribute. These plants also showing dwarfism have their particular mechanisms that allow them to bloom at low temperatures.
Snowball plants are characterized by very dense trichomes on tightly packed bracts of inflorescences that keep the inside warmer than the cold, outer environment; plants with "glasshouse-like" morphology have developed into large translucent cream-colored bracts that cover the inflorescences. These bracts also play a critical role in protecting pollen grains from damage by low temperatures (Omori et al. 2008, Wen et al. 2014), and maintaining warmth inside the inflorescence (Terashima et al. 1993). These morphological adaptations of inflorescences for plants of the plateau that develop at low temperatures are a convergent evolution as a result of natural selection (Tsukaya and Tsuge 2001; Wen et al. 2014). All in all, it may be easier to understand why the reconstructed temperatures are so higher than the observed temperatures, since we use the air temperature to define the observed MAT, MTWA and MTCO, in place of the temperature of blossoming.

\section{Perspective}

The climate reconstructions from modern pollen samples on Qinghai-Tibetan Plateau (Zhang et al. 2015) suggest that precipitation reconstructions are more accurate than temperature reconstructions. The large uncertainties of climate reconstructions by the method of CA arise by reasons of the contamination of long-distance transported anemophilous tree pollen, the complex hydrological dynamic among rainfall, snowmelt and permafrost and the discrepancies between the air temperature and the

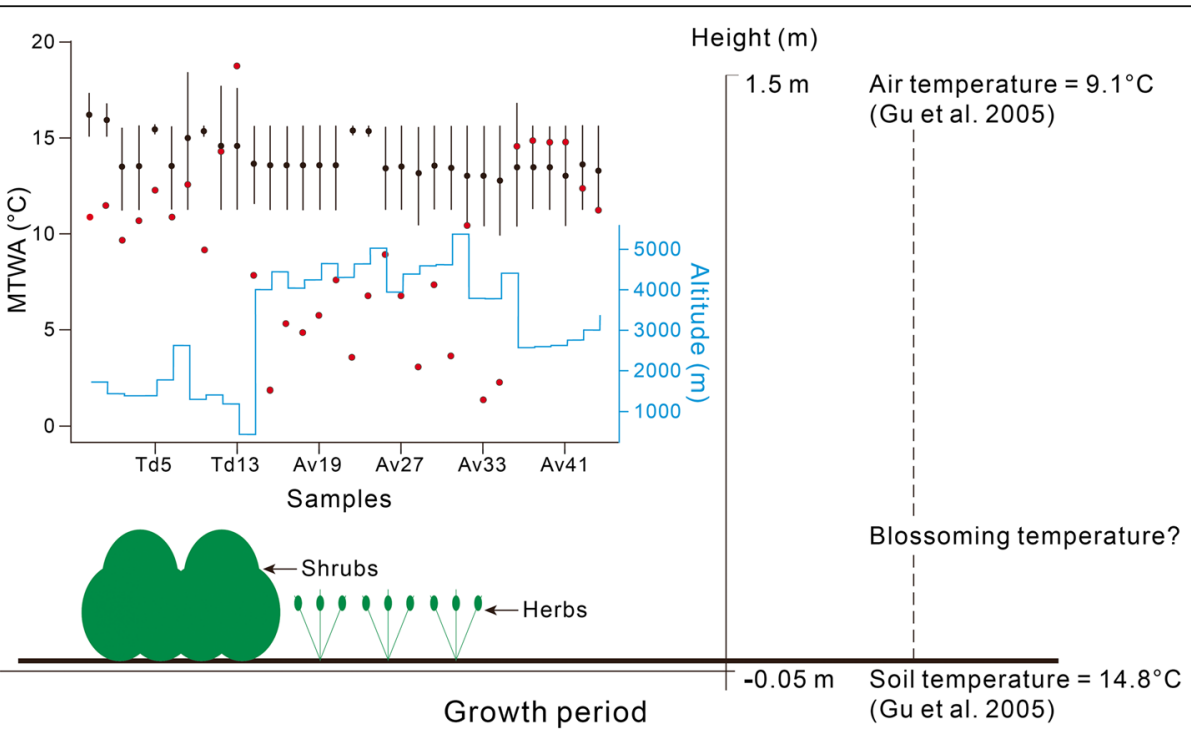

Fig. 5 Schematic illustration of the possible explanation of discrepancy between the reconstructed MTWA (mean temperature of the warmest month) and observed values. The MTWA reconstruction result is redrawn from non-trees reconstructions of Zhang et al. 2015. Vertical bars with black points indicate the coexistence intervals and their medians for reconstructed MTWA. The observations of MTWA are indicated as red points. The altitudes of sampling sites are also shown in blue. The blossoming of shrubs and herbs in Qinghai-Tibetan Plateau may response to the air temperature somewhere less than this height, rather than the air temperature at $1.5 \mathrm{~m}$. Here it is named as the blossoming temperature. Air temperature and soil temperature at $5 \mathrm{~cm}$ depth during the growth period of plants are from Gu et al. 2005 
temperature of plant blossoming. Not only these factors influence the accuracy of modern climate reconstructions on the plateau, but also the reconstruction method of CA itself needs to be evaluated (Zhang et al. 2015) and improved (Grimm and Denk 2012; Grimm et al. 2016). The ability of CA to reconstruct modern climate does not guarantee that this approach will offer satisfying reconstructions of palaeoclimates on the plateau. Past climate changes on Qinghai-Tibetan Plateau may have been even more complex than anticipated (An et al. 2001, 2011; Zhao et al. 2015). It may take a long time to sort out the complicated influences from the abovementioned factors before realistic palaeoclimate reconstructions based on the CA are obtained. Nevertheless, our explorations suggest that it is worthwhile to apply the Coexistence Approach to the palaeorecords of the plateau and have provided some new insights of what factors may seriously affect the (palaeo-)climate reconstructions. After all, reliable palaeoclimatic data are essential for interpreting the controversially discussed uplift history of the Qinghai-Tibetan Plateau (e.g. Chung et al. 1998; An et al. 2001; Qiang et al. 2001; Spicer et al. 2003; DeCelles et al. 2007; Sun et al. 2014).

\section{Abbreviations}

AP: Arboreal pollen; CA: Coexistence approach; MAP: Mean annual precipitation; MAT: Mean annual temperature; MTCO: Mean temperature of the coldest month; MTWA: Mean temperature of the warmest month; NAP: Non-arboreal pollen; NTR: Non-tree reconstruction; RMSE: Root mean squared error; SRTM: Shuttle radar topography mission; WR: Weighted reconstruction

\section{Acknowledgements}

We would like to thank Dr. Angela Bruch, Dr. Guang-Qi Li and Dr. Chao Zhao for their comments and suggestions. This work was supported by National Natural Science Foundation of China (Grant No. 41861003) and Basic Work Special Project of the National Ministry of Science and Technology of China (Grant No. 2013FY111500).

\section{Authors' contributions}

ZYZ and CSL designed the study. ZYZ carried out the data analysis and prepared the manuscript. DMC prepared the references and $\mathrm{WH}$ helped make Fig. 1. All authors participated in the results discussion. All authors read and approved the final manuscript.

\section{Competing interests}

The authors declare that they have no competing interests.

\section{Publisher's Note}

Springer Nature remains neutral with regard to jurisdictional claims in published maps and institutional affiliations.

Received: 24 April 2018 Accepted: 7 August 2018

Published online: 08 January 2019

\section{References}

An, Z.S., S.C. Clemens, J. Shen, X.K. Qiang, Z.D. Jin, Y.B. Sun, W.L. Prell, J.J. Luo, S.M. Wang, H. Xu, Y.J. Cai, W.J. Zhou, X.D. Liu, W.G. Liu, Z.G. Shi, L.B. Yan, X.Y. Xiao, H. Chang, F. Wu, L. Ai, and F.Y. Lu. 2011. Glacial-interglacial Indian summer monsoon dynamics. Science 333 (6043): 719-723.

An, Z.S., J.E. Kutzbach, W.L. Prell, and S.C. Porter. 2001. Evolution of Asian monsoons and phased uplift of the Himalaya-Tibetan plateau since Late Miocene times. Nature 411 (6833): 62-66.
Böhme, M., A.A. Bruch, and A. Selmeier. 2007. The reconstruction of early and middle Miocene climate and vegetation in southern Germany as determined from the fossil wood flora. Palaeogeography, Palaeoclimatology, Palaeoecology 253 (1-2): 91-114.

Bruch, A.A., T. Utescher, V. Mosbrugger, I. Gabrielyan, and D.A. Ivanov. 2006. Late Miocene climate in the circum-alpine realm - A quantitative analysis of terrestrial palaeofloras. Palaeogeography, Palaeoclimatology, Palaeoecology 238: $270-280$.

Cable, D.R. 1969. Competition in the semidesert grass-shrub type as influenced by root systems, growth habits, and soil moisture extraction. Ecology 50 (1): 27-38.

Chen, W.N., Y. Wu, N. Wu, and P. Luo. 2008. Effect of snow-cover duration on plant species diversity of alpine meadows on the eastern Qinghai-Tibetan plateau. Journal of Mountain Science 5 (4): 327-339.

Chung, S.L., C.H. Lo, T.Y. Lee, Y.Q. Zhang, Y.W. Xie, X.H. Li, K.L. Wang, and P.L. Wang. 1998. Diachronous uplift of the Tibet plateau starting 40 Myr ago. Nature 394 (6695): 769-773.

Cour, P., Z. Zheng, D. Duzer, M. Calleja, and Z. Yao. 1999. Vegetational and climatic significance of modern pollen rain in northwestern Tibet. Review of Palaeobotany and Palynology 104 (3-4): 183-204.

DeCelles, P.G., J. Quade, P. Kapp, M. Fan, D.L. Dettman, and L. Ding. 2007. High and dry in Central Tibet during the late Oligocene. Earth and Planetary Science Letters 253 (3-4): 389-401.

Erdei, B., L. Hably, M. Kázmér, T. Utescher, and A.A. Bruch. 2007. Neogene flora and vegetation development of the Pannonian domain in relation to palaeoclimate and palaeogeography. Palaeogeography, Palaeoclimatology, Palaeoecology 253 (1-2): 115-140.

Farr, T.G., P.A. Rosen, E. Caro, R. Crippen, R. Duren, S. Hensley, M. Kobrick, M. Paller, E. Rodriguez, L. Roth, D. Seal, S. Shaffer, J. Shimada, J. Umland, M. Werner, M. Oskin, D. Burbank, and D. Alsdorf. 2007. The shuttle radar topography Mission. Reviews of Geophysics 45 (2): G2004. https://doi.org/10.1029/2005RG000183.

Gebka, M., V. Mosbrugger, H.D. Schilling, and T. Utescher. 1999. Regional-scale palaeoclimate modelling on soft proxy-data basis - An example from the Upper Miocene of the lower Rhine embayment. Palaeogeography, Palaeoclimatology, Palaeoecology 152 (3-4): 225-258.

Grein, M., T. Utescher, V. Wilde, and A. Roth-Nebelsick. 2011. Reconstruction of the middle Eocene climate of Messel using palaeobotanical data. Neues Jahrbuch für Geologie und Paläontologie - Abhandlungen 260 (3): 305-318.

Grimm, G.W., J.M. Bouchal, T. Denk, and A. Potts. 2016. Fables and foibles: A critical analysis of the Palaeoflora database and the coexistence approach for palaeoclimate reconstruction. Review of Palaeobotany and Palynology 233: 216-235.

Grimm, G.W., and T. Denk. 2012. Reliability and resolution of the coexistence approach - A revalidation using modern-day data. Review of Palaeobotany and Palynology 172: 33-47.

Grimm, G.W., and A.J. Potts. 2016. Fallacies and fantasies: The theoretical underpinnings of the coexistence approach for palaeoclimate reconstruction. Climate of the Past 12 (3): 611-622.

Gu, S., Y.H. Tang, X.Y. Cui, T. Kato, M.Y. Du, Y.N. Li, and X.Q. Zhao. 2005. Energy exchange between the atmosphere and a meadow ecosystem on the Qinghai-Tibetan plateau. Agricultural and Forest Meteorology 129 (3): 175-185.

Hancock, P.A., and M.F. Hutchinson. 2006. Spatial interpolation of large climate data sets using bivariate thin plate smoothing splines. Environmental Modelling and Software 21 (12): 1684-1694.

Hao, H., D.K. Ferguson, G.P. Feng, A. Ablaev, Y.F. Wang, and C.S. Li. 2010. Early Paleocene vegetation and climate in Jiayin. NE China. Climatic Change 99 (3): 547-566.

Harris, I., P.D. Jones, T.J. Osborn, and D.H. Lister. 2013. Updated high-resolution grids of monthly climatic observations - The CRU TS3.10 dataset. International Journal of Climatology 34 (3): 623-642.

Jacques, F.M.B., S.X. Guo, T. Su, Y.W. Xing, Y.J. Huang, Y.S. Liu, D.K. Ferguson, and Z.K. Zhou. 2011. Quantitative reconstruction of the Late Miocene monsoon climates of Southwest China: A case study of the Lincang flora from Yunnan Province. Palaeogeography, Palaeoclimatology, Palaeoecology 304 (3-4): 318-327.

Jiang, H., and Z. Ding. 2009. Spatial and temporal characteristics of Neogene palynoflora in China and its implication for the spread of steppe vegetation. Journal of Arid Environments 73 (9): 765-772.

Kambatuku, J.R., M.D. Cramer, and D. Ward. 2013. Overlap in soil water sources of savanna woody seedlings and grasses. Ecohydrology 6 (3): 464-473.

Kang, S.C., Y.P. Yang, L.P. Zhu, Y.M. Ma, and W.Q. Ma. 2011. Modern environmental processes and changes of the Nam Co Basin, Tibetan plateau. Beijing: China Meteorological Press (in Chinese). 
Kita, Y., F. Kazumi, M. Ito, H. Ohba, and M. Kato. 2004. Molecular phylogenetic analyses and systematics of the genus Saussurea and related genera (Asteraceae, Cardueae). Taxon 53 (3): 679-690.

Knoop, W.T., and B.H. Walker. 1985. Interactions of woody and herbaceous vegetation in a southern African savanna. Journal of Ecology 73 (1): 235-253.

Li, J.F., D.K. Ferguson, J. Yang, G.P. Feng, A.G. Ablaev, Y.F. Wang, and C.S. Li. 2009. Early Miocene vegetation and climate in Weichang District, North China. Palaeogeography, Palaeoclimatology, Palaeoecology 280 (1-2): 47-63.

Liu, X.D., and B.D. Chen. 2000. Climatic warming in the Tibetan plateau during recent decades. International Journal of Climatology 20 (14): 1729-1742.

Lu, X.M., M. Herrmann, V. Mosbrugger, T.D. Yao, and L.P. Zhu. 2010. Airborne pollen in the Nam Co Basin and its implication for palaeoenvironmental reconstruction. Review of Palaeobotany and Palynology 163 (1-2): 104-112.

Mosbrugger, V., and T. Utescher. 1997. The coexistence approach — A method for quantitative reconstructions of tertiary terrestrial palaeoclimate data using plant fossils. Palaeogeography, Palaeoclimatology, Palaeoecology 134: 61-86.

Omori, Y., H. Takayama, and H. Ohba. 2008. Selective light transmittance of translucent bracts in the Himalayan giant glasshouse plant Rheum nobile Hook. f. \& Thomson (Polygonaceae). Botanical Journal of the Linnean Society 132 (1): 19-27.

Pross, J., S. Klotz, and V. Mosbrugger. 2000. Reconstructing palaeotemperatures for the early and middle Pleistocene using the mutual climatic range method based on plant fossils. Quaternary Science Reviews 19 (17-18): 1785-1799.

Qian, Y.F., Y.Q. Zheng, Y. Zhang, and M.Q. Miao. 2003. Responses of China's summer monsoon climate to snow anomaly over the Tibetan plateau. International Journal of Climatology 23 (6): 593-613.

Qiang, X.K., Z.X. Li, C.McA. Powell, and H.B. Zheng. 2001. Magnetostratigraphic record of the Late Miocene onset of the east Asian monsoon, and Pliocene uplift of northern Tibet. Earth and Planetary Science Letters 187 (1-2): 83-93.

Qin, F., D.K. Ferguson, R. Zetter, Y.F. Wang, S. Syabryaj, J.F. Li, J. Yang, and C.S. Li. 2011. Late Pliocene vegetation and climate of Zhangcun region, Shanxi, North China. Global Change Biology 17 (5): 1850-1870.

Quan, C., Y.S. Liu, and T. Utescher. 2011. Paleogene evolution of precipitation in northeastern China supporting the middle Eocene intensification of the east Asian monsoon. Palaios 26 (11): 743-753.

Sharma, P., N. Sharma, and R. Deswal. 2005. The molecular biology of the lowtemperature response in plants. Bioessays 27 (10): 1048-1059.

Song, X.Y., R.A. Spicer, J. Yang, Y.F. Yao, and C.S. Li. 2010. Pollen evidence for an Eocene to Miocene elevation of central southern Tibet predating the rise of the high Himalaya. Palaeogeography, Palaeoclimatology, Palaeoecology 297 (1): 159-168

Spicer, R.A., N.B.W. Harris, M. Widdowson, A.B. Herman, S.X. Guo, P.J. Valdes, J.A Wolfe, and S.P. Kelley. 2003. Constant elevation of southern Tibet over the past 15 million years. Nature 421 (6923): 622-624.

Sun, J.M., Q.H. Xu, W.M. Liu, Z.Q. Zhang, L. Xue, and P. Zhao. 2014. Palynological evidence for the latest Oligocene-early Miocene paleoelevation estimate in the Lunpola Basin, Central Tibet. Palaeogeography, Palaeoclimatology, Palaeoecology 399: 21-30

Terashima, I., T. Masuzawa, and H. Ohba. 1993. Photosynthetic characteristics of a giant alpine plant, Rheum nobile Hook. f. et Thoms. And of some other alpine species measured at 4300 m, in the eastern Himalaya, Nepal. Oecologia 95 (2): 194-201

Tsukaya, $H_{\text {. }}$ and T. Tsuge. 2001. Morphological adaptation of inflorescences in plants that develop at low temperatures in early spring: The convergent evolution of "downy plants". Plant Biology 3 (5): 536-543.

Utescher, T., A.A. Bruch, B. Erdei, L. François, D. Ivanov, F.M.B. Jacques, A.K. Kern, Y. S. Liu, V. Mosbrugger, and R.A. Spicer. 2014. The coexistence approach Theoretical background and practical considerations of using plant fossils for climate quantification. Palaeogeography, Palaeoclimatology, Palaeoecology 410: 58-73.

Walter, H. 1971. Ecology of tropical and subtropical vegetation. Edinburgh: Oliver and Boyd.

Wang, H., I.C. Prentice, and J. Ni. 2013. Data-based modelling and environmental sensitivity of vegetation in China. Biogeosciences 10 (9): 5817-5830.

Wen, J., J.Q. Zhang, Z.L. Nie, Y. Zhong, and H. Sun. 2014. Evolutionary diversifications of plants on the Qinghai-Tibetan plateau. Frontiers in Genetics 5: 4. https://doi.org/10.3389/fgene.2014.00004

Wilf, P., S.L. Wing, D.R. Greenwood, and C.L. Greenwood. 1998. Using fossil leaves as paleoprecipitation indicators: An Eocene example. Geology 26 (3): 203-206.

Wu, J., K.X. Zhang, Y.D. Xu, G.C. Wang, C.N. Garzione, J. Eiler, P.H. Leloup, P. Sorrel, and G. Mahéo. 2018. Paleoelevations in the Jianchuan Basin of the southeastern Tibetan plateau based on stable isotope and pollen grain analyses. Palaeogeography, Palaeoclimatology, Palaeoecology (in press. https:// doi.org/10.1016/j.palaeo.2018.03.030.

Wu, Z.Y., and T.Y. Ding. 1999. Seed Plants of China. Kunming: Yunnan Science and Technology Press (Electronic publication in Chinese).

Xia, K., T. Su, Y.S. Liu, Y.W. Xing, F.M.B. Jacques, and Z.K. Zhou. 2009. Quantitative climate reconstructions of the late Miocene Xiaolongtan megaflora from Yunnan, Southwest China. Palaeogeography, Palaeoclimatology, Palaeoecology 276: 80-86.

Yang, J., Y.F. Wang, R.A. Spicer, V. Mosbrugger, C.S. Li, and Q.G. Sun. 2007. Climatic reconstruction at the Miocene Shanwang Basin, China, using leaf margin analysis, CLAMP, coexistence approach, and overlapping distribution analysis. American Journal of Botany 94 (4): 599-608.

Yao, Y.F., S. Bera, D.K. Ferguson, V. Mosbrugger, K.N. Paudayal, J.H. Jin, and C.S. Li. 2009. Reconstruction of paleovegetation and paleoclimate in the early and middle Eocene, Hainan Island, China. Climatic Change 92 (1): 169-189.

Ying, Z.X., J.B. Liao, Y.J. Liu, S.C. Wang, H. Lu, L. Ma, D.D. Chen, and Z.Q. Li. 2017. Modelling tree-grass coexistence in water-limited ecosystems. Ecological Modelling 360: 387-398.

Yu, G., L.Y. Tang, X.D. Yang, X.K. Ke, and S.P. Harrison. 2001. Modern pollen samples from alpine vegetation on the Tibetan plateau. Global Ecology and Biogeography 10 (5): 503-519.

Zhang, Q.Q., T. Smith, J. Yang, and C.S. Li. 2016. Evidence of a cooler continental climate in East China during the warm early Cenozoic. PLoS One 11 (5): e155507.

Zhang, X.S. 2007. Vegetation map of the People's republic of China $(1: 1,000,000)$ Beijing: Geological Publishing House.

Zhang, Y.J., L. Duo, Y.Z. Pang, V.A. Felde, H.H. Birks, and H.J.B. Birks. 2018. Modern pollen assemblages and their relationships to vegetation and climate in the Lhasa Valley, Tibetan plateau, China. Quaternary International 467 (Part B): 210-221.

Zhang, Y.L., B.Y. Li, and D. Zheng. 2002. A discussion on the boundary and area of the Tibetan plateau in China. Geographical Research 21 (1): 1-8 (in Chinese with English abstract)

Zhang, Y.S., T. Ohata, and T. Kadota. 2003. Land-surface hydrological processes in the permafrost region of the eastern Tibetan plateau. Journal of Hydrology 283 (1): 41-56.

Zhang, Z.Y. 2016. Comparison of Techniques to Reconstruct Palaeoclimates of China [doctoral dissertation]. Sydney: Macquarie University.

Zhang, Z.Y., S.P. Harrison, V. Mosbrugger, D.K. Ferguson, K.N. Paudayal, A. Trivedi, and C.S. Li. 2015. Evaluation of the realism of climate reconstruction using the coexistence approach with modern pollen samples from the QinghaiTibetan plateau. Review of Palaeobotany and Palynology 219: 172-182.

Zhang, Z.Y., and C.S. Li. 2017. Distributional patterns of anemophilous tree pollen indicating the pathways of Indian monsoon through Qinghai-Tibetan plateau. Journal of Palaeogeography 6 (4): 352-358.

Zhao, Y., U. Herzschuh, and Q. Li. 2015. Complex vegetation responses to climate change on the Tibetan plateau: A paleoecological perspective. National Science Review 2 (4): 400-402.

\section{Submit your manuscript to a SpringerOpen ${ }^{\circ}$ journal and benefit from:}

- Convenient online submission

- Rigorous peer review

- Open access: articles freely available online

- High visibility within the field

- Retaining the copyright to your article

Submit your next manuscript at $>$ springeropen.com 